\title{
Performance evaluation of different micro-CHP configurations in real life conditions and the influence of part load behaviour
}

\author{
Ivan Verhaert ${ }^{1,}$, Freek Van Riet ${ }^{1}$, Robin Baetens ${ }^{1}$, Margot De Pauw ${ }^{2}$ and Michiel Van Erdeweghe ${ }^{2}$ \\ ${ }^{1}$ University of Antwerp, Faculty of Applied Engineering, Energy and Material in Infrastructure and Buildings, Campus \\ Groenenborger, Groenenborgerlaan 171, 2020 Antwerp, building Z. \\ ${ }^{2}$ Thomas More Kempen, Kenniscentrum Energie, Kleinhoefstraat 4, 2440 Geel.
}

\begin{abstract}
Micro-cogeneration (micro-CHP) is an emerging technology to reduce the non-renewable energy demand in buildings and reduce peak loads in the grid. Within building applications internal combustion engines, Stirling engines and CHPs based on fuel cell technology are mostly used. The heat and electricity demand here is often characterized by a strong fluctuation over time. The design and control of micro-CHP in buildings is therefore often more challenging in order to achieve its nominal efficiency. In a recently ended research project, different micro-CHP-technologies were evaluated based on on-site measurement campaigns. In practice, micro-CHP is hardly ever used as single technology to deliver the necessary heat. A poor hydronic design can strongly reduce the number of operating hours of the CHP and even its performance, which is influenced by e.g. return temperature. In this paper the performance and behaviour of different technologies are discussed with a strong focus on the part load and start-stop behaviour. The necessary insights are provided with respect to system integration and control and are illustrated with a discussion on the executed measurement campaign in the region of Flanders.
\end{abstract}

\section{Introduction}

Cogeneration is an efficient technology, which proves to be complementary to other and renewable energy systems[1]-[3]. Within buildings and more specific 'flexible buildings' micro-cogeneration has an interesting potential to meet future and present energy demands, as it not only is able to meet the local heat demand, but is also capable to reduce peak loads in the grid.

As several interpretations can be given to micro-CHP (micro combined heating and power), a definition is given in [4] by the Flemish parliament, defining microCHP as a CHP-unit with an electrical power output of less than $50 \mathrm{~kW}$. Other definitions exist, but within the objective of this paper, this definition will be used to categorize CHP-units as micro-CHP or not. As size can differ from $0.5 \mathrm{~kW}$ to $50 \mathrm{~kW}$, several technologies are available. Within building applications internal combustion engines, Stirling engines and CHPs based on fuel cell technology are most commonly used in the Belgian market. However, despite the benefits, like grid flexibility, not all installations perform well, which led to a limited roll-out of the technology.

The project 'micro-CHP' , funded by the Flemish government, aimed to clarify the problems which ought to be encountered and to list up the key criteria to install a successful CHP-unit [16].

\section{Scope and Methodology}

A proper installation starts with selecting and sizing the proper technology. In order to select the right technology for the application different criteria and strategies can be applied [5], [6]. In a first attempt to select the best or right technology the power-to-heat ratio is an important indicator. Ideally one could say that both energy demand profile of the building and CHP have a similar power-to-heat-ratio. Based on a market evaluation Figure 1 one was built, dividing the different brands, which are available on the Belgian market or expected to be, into three groups, namely fuel cells (FCs), Stirling and internal combustion engines (ICEs).

As Figure 1 illustrates, it is clear that fuel cells have a high power to heat ratio, which makes them suitable for well insulated buildings [7], whereas Stirling engines have the lowest power to heat ratio and are meant for renovation market. Figure 1 also illustrates the primary energy saving potential to a conventional energy supply, which is represented by the lower dotted line. The conventional heat and power supply for a building exists out of a local heat boiler, with about $90 \%$ efficiency and an electricity supply from the grid for which a conversion efficiency of about $40 \%$ (HHV) is assumed here. The upper dotted line represents a utilization ratio of $100 \%$, so normally all CHPs should be under this line as it represents the physical maximum. It is clear that the reported efficiencies in technical data sheets (even recalculated to higher heating values if necessary) cannot be taken for granted.

In general there is sometimes a large discrepancy between reported and actual efficiency. To understand these differences a number of test cases were monitored and evaluated with a comparison to reported efficiencies. To understand these differences the influence of the part load behaviour is discussed with afterwards some reflections on the importance of a good hydronic design.

* Corresponding author: ivan.verhaert@uantwerpen.be 


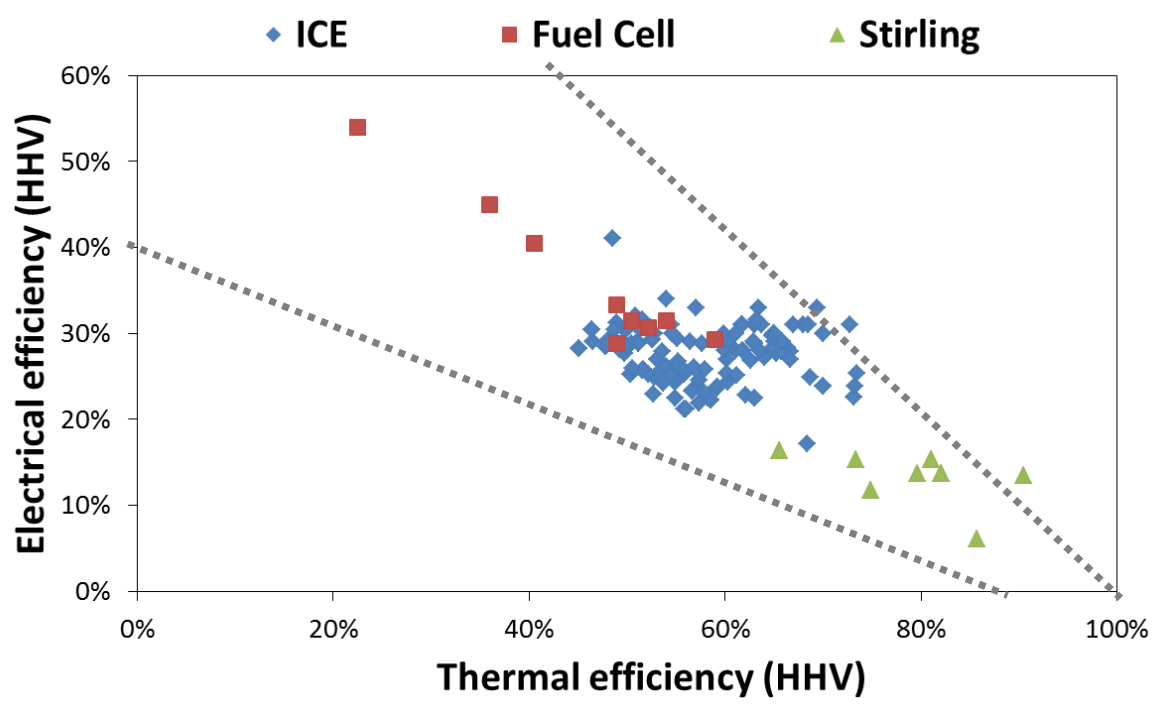

Fig. 1. Market study on reported efficiencies (re-calculated to higher heating values (HHV) if necessary) for three different groups of micro-CHPs: Internal Combustion Engines (ICE), Fuel Cell based micro-CHPs and CHP based on Stirling principle. The efficiencies are put in perspective with a line representing the conventional power supply (lower dotted line) and the maximum physically possible (upper line)

\section{Measurement Campaign}

A (almost) universal lay-out for the measurement setup is shown in Figure 2. As can be seen, there is a gas measurement and an electricity meter which measures production(+) and auxiliary equipment(-). The thermal energy use (heat) exist out of heat demand for space heating (SH) and domestic hot water production (DHW). The heat meters are set-up before the storage tank (Gross) and after the tank (Net), to evaluate the influence of stand-by losses on overall efficiency. Finally the data is sent every 15 minutes to the cloud for further analysis.
Table 1 presents an overview of the case studies and Table 2 the results. As can be noted, in some cases an intervention was executed based on the measurements. The results were therefore split up into two different periods. From these results, it is clear that on-site performance differs considerably from the performance as reported by manufacturers. In the next section, these differences are explained by discussing the part load and start-stop behaviour.

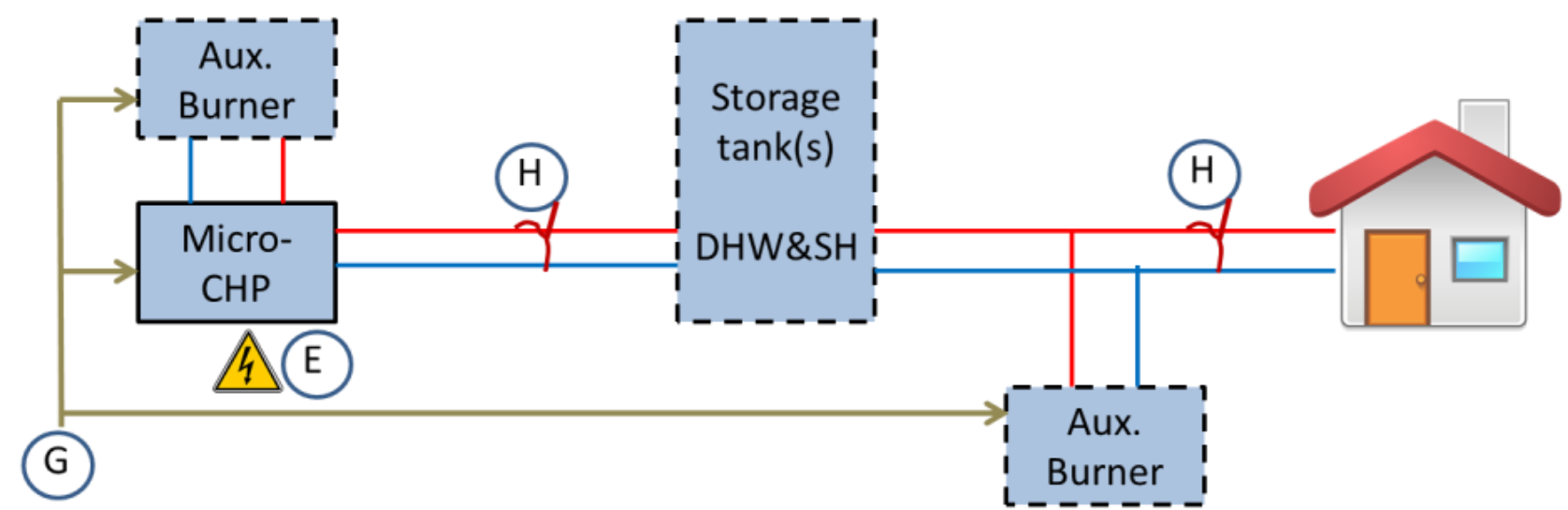

Fig. 2. Generalized measurement set-up, with an indication (circles with a letter) of how and where the energy flows where measured (G: Gas; E: Net and Gross electricity; H: Gross and Net thermal energy).The dotted parts are components which are only present in some set-ups (See Table 1)

\footnotetext{
* Corresponding author: ivan.verhaert@uantwerpen.be
} 
Table 1. Overview of the studied cases

\begin{tabular}{|l|l|l|}
\hline Case & Description of the set-up & Application \\
\hline ICE 1 & Large storage tank 1000L + extra DHW-boiler & Offices + Household \\
ICE 2a & CHP with storage tank (behind heat exchanger) + parallel aux.boiler & Swimming pool \\
ICE 2b & Similar but no heat exchanger & Household (SH) \\
Stirling 1 & CHP with 500L storage + EXTRA parallel boiler & Household (SH+DHW) \\
Stirling 2 & CHP (combi) with storage tank and DHW tank & Household (SH+DHW) \\
Stirling 3 & CHP with 1 storage tank (500L) with Heat exchangers for SH and DHW & Household (SH+DHW) \\
Stirling 4a & CHP with 1 storage tank (500L) with Heat exchangers for SH and DHW & Household (SH+DHW) \\
Stirling 4b & \multicolumn{1}{|l}{ CHP with 1 storage tank (750L) with Heat exchangers for SH and DHW } & SH (+ swimming pool) \\
Stirling 5 & CHP connected to large tank &
\end{tabular}

Table 2. Overview of the results of the measurement campaign, illustrating the difference between reported efficiency (Ref), Efficiency based on CHP output (Gross) and (net) efficiency, which includes storage losses and auxiliary equipment. The uncertainty of the measurements are expressed as (error). To allow critical reflection, data which were indirectly (calculated or from a source with limited access for further specifications) achieved are in italic.

\begin{tabular}{|c|c|c|c|c|c|c|c|c|c|}
\hline \multirow[b]{2}{*}{ Case } & \multirow{2}{*}{$\begin{array}{l}\text { Size } \\
\text { kWe }\end{array}$} & \multicolumn{4}{|c|}{ El. Eff. (\%) } & \multicolumn{4}{|c|}{ Th. Eff (\%) } \\
\hline & & Ref & gross & net & error & Ref & gross & net & error \\
\hline ICE 1 & 5,5 & $24 \%$ & $22 \%$ & $22 \%$ & $0,5 \%$ & $55 \%$ & $57 \%$ & $53 \%$ & $1,1 \%$ \\
\hline ICE $2 a$ & 50 & $31 \%$ & $25 \%$ & $25 \%$ & $0,6 \%$ & $49 \%$ & $42 \%$ & $38 \%$ & $1,0 \%$ \\
\hline ICE $2 b$ & 50 & $31 \%$ & $30 \%$ & $30 \%$ & $0,6 \%$ & $49 \%$ & $45 \%$ & $44 \%$ & $1,0 \%$ \\
\hline Stirling 1 & 1 & $13 \%-4 \%$ & $5 \%$ & $5 \%$ & $0,2 \%$ & $74-81 \%$ & $52 \%$ & $38 \%$ & $1,8 \%$ \\
\hline Stirling 2 & 1 & $13 \%-4 \%$ & $6 \%$ & $5 \%$ & $0,2 \%$ & $74-81 \%$ & $60 \%$ & $56 \%$ & $1,8 \%$ \\
\hline Stirling 3 & 1 & $12 \%$ & $2 \%$ & $1 \%$ & $0,2 \%$ & $88 \%$ & $100 \%$ & $78 \%$ & $1,8 \%$ \\
\hline Stirling $4 a$ & 1 & $12 \%$ & $0 \%$ & $-1 \%$ & $0,2 \%$ & $88 \%$ & $93 \%$ & $74 \%$ & $1,8 \%$ \\
\hline Stirling $4 b$ & 1 & $12 \%$ & $10 \%$ & $9 \%$ & $0,2 \%$ & $88 \%$ & $89 \%$ & $81 \%$ & $1,8 \%$ \\
\hline Stirling 5 & 1 & $15 \%$ & $9 \%$ & $9 \%$ & $0,3 \%$ & $81 \%$ & $78 \%$ & $70 \%$ & $1,6 \%$ \\
\hline SOFC & 1,5 & $54 \%$ & $48 \%$ & $46 \%$ & $1,1 \%$ & $23 \%$ & $15 \%$ & $6 \%$ & $0,5 \%$ \\
\hline
\end{tabular}

\section{Comparison of Part Load Behaviour}

\subsection{Stirling Engines}

In literature several papers already made comments on their part load and start-stop behaviour [9], [10]. In general 4 different operating regimes exist: stand-by, start-up, nominal operation and cool-down.

As long as the Stirling is not working or waiting to be activated some off-mode power consumption, about $10_{-}$ $15 \mathrm{~W}$, due to the control system is monitored [9]. No heat is delivered nor fuel is consumed.

During start-up the fuel consumption is about $20 \%$ higher than during nominal operation to ensure a faster warm-up of the engine. This higher fuel consumption drops after 3-4 minutes and reaches the stationary fuel consumption after about 20 minutes [11]. As most fuelenergy is used to heat up the engine, also thermal power output is not yet optimal. The heat delivered by the engine starts to increase after 2-3 minutes. After 15-20 minutes a small maximum heat output is measured which drops again to reach a stationary heat output after 30 minutes [10]. Despite the higher fuel consumption and lack of heat delivery during the first minutes, no net electric power is yet generated in this time. On the contrary, the negative power output is even increased, about $85 \mathrm{~W}$, as the auxiliary power is needed not only for measuring and control, but also to start up pumps and fans. Just before net power delivery, a high negative peak power to synchronize the generator is sometimes noticed. Net power delivery occurs after 4 minutes. After that the electric power output slowly increases and reaches its stationary power output after 20-25 minutes [11]. In general it can be concluded that the start-up takes at least 15 minutes before savings are within range.

During nominal operation there are also some other influencing parameters. In [10] it is shown that higher flow rate and lower return temperature have a positive effect on both electrical and thermal efficiency as they ensure a better heat release. 
When shutting down, the fuel consumption stops immediately and the alternator slows down. Hence the electricity production drops linear to become negative after 4 minutes. 18 minutes after the initiation of the shut-down process, the consumption falls back to its stand-by power consumption, when the pumps and fans stop [11]. As the engine is still warm when shutting down, the first 10 minutes the thermal power output does not decrease whatsoever, after that it drops rapidly (15 minutes) to almost zero [10].

From the point of view of energy efficiency, this review on start-up behaviour illustrates clearly that a Stirling engine has a poor start and stopping behaviour and therefore needs to be used where a constant heat load (at low temperature) is possible.

In practice all investigated Stirling engines are serially connected to an auxiliary burner and a storage tank. This last is to ensure a constant heat load. However, the stand-by losses, illustrated by the difference between gross and net thermal efficiency (Table 2), are a drawback of this solution. In case 2 this is partially addressed by switching the ' $\mathrm{CHP}+$ buffer' off in summer, when the heat load is too small. Besides this, the auxiliary burner sometimes takes over too soon (case 4). After some adjustments in hydronics and control this was encountered, with positive effect on efficiency (case $4 a-4 b$ ). Also in case 3 this problem occurs. From the data it is seen that the Stirling only runs in summer. In winter, it does not deliver enough heat, so the relatively big auxiliary burner comes in and takes over the complete heat demand, due to poor integration or control.

The Stirling has limited saving potential and poor start-stop behaviour. It therefore needs a storage tank (with additional loss) to ensure a smooth heat load, causing relatively low efficiencies.

\subsection{Internal Combustion Engines}

Internal combustion engines have a similar behaviour as Stirling engines as they are both heat driven.

During stand-by $100 \mathrm{~W}$ is consumed for a unit with nominal power of $25 \mathrm{kWe}$ [6], $90 \mathrm{~W}$ for $6 \mathrm{kWe}$ [7].

When starting up, the engine has to be warmed-up. Therefore, most installations are equipped with a threeway valve that ensures a minimal temperature of the ingoing water. This minimal temperature is a setting of the internal control logics of the CHP unit (typically $65^{\circ} \mathrm{C}$ ). This results in a delay of the response of the useful thermal power. Besides the internal settings, the length of this delay also depends on the temperature of the engine at the beginning of the start-up (and in case of electric-lead mode the demanded electrical power [12]). E.g., for a unit of $4.7 \mathrm{kWe}$ [9] this resulted in a delay of 10 minutes for a cold start-up and 3 minutes for a warm start-up. It then lasts 5 to 30 minutes to reach a stationary state [9].

Also electrical power has a delay after switching from stand-by to start-up: $60-75$ seconds according to [12], and 10 seconds according to [13] and [14]. In these references, the power changes with a clear step. However, other data [9] shows a delay of 1 minute, then producing at half of the nominal power, and 2-5 minutes later-depends, again, on the temperature of the engine at beginning of start-up- producing at full load.

Also gas consumption dynamics during start-up differ between different units. [14] found a step change during start-up, without higher consumption in the beginning. [12] found a lower gas consumption than in normal mode during the beginning of the start-up phase when no electricity is produced. Once electricity is produced, the gas consumption shows an overshoot, only to converge after 200 seconds. In general, this overconsumption is also dependent on the engine temperature at the beginning of the start-up.

From the point of view from hydraulic integration, the major difference with a Stirling engine, is that the electrical efficiency of an ICE is independent of the return water temperature. Also, ICE-based CHPs operate normally under a constant water flow rate according to its own circuit, and therefore this will not affect the performance. However, the return water temperature affects the total efficiency by affecting the thermal efficiency [14]. When the CHP is heat-lead, typically the modulation is controlled depending on the return temperature (typically lowering above $70^{\circ} \mathrm{C}$ and shutting down above $75^{\circ} \mathrm{C}$ ). This part load behaviour affects both electric and thermal efficiency. E.g. for a $6 \mathrm{~kW}_{\mathrm{e}}$ unit, it was shown that the electric efficiency is 7 and 20 percentage points lower when comparing 100\% load with $55 \%$ and $10 \%$ of the full load [7]. On the other hand, the thermal efficiency increased with the same percentage points. Comparable trends can be found in [14] and [9].

During cool down, the pump stays on and the threeway valve stays open to release the residual heat of the engine. The gas consumption stops immediately and the electricity production lowers fast to stop after a few seconds [15],[14] or minutes [9].

For the first case of internal combustion engines (Table 2), the results were as expected as the CHP had long running cycles. In case 2.a (Table 2), a larger number of start-ups (up to daily maximum) and short running cycles were noticed, which explains the low performance. Yet, long running hours are normally easy to ensure within a swimming pool. However, the CHP was additionally implemented in an existing production site (consisting of boilers). Apparently, this resulted in a poor hydronic integration. Indeed, a heat exchanger was installed between the existing circuit and the CHP circuit. Due to this either poorly sized or even 
unnecessary heat exchanger, the CHP could not release its heat and received high return temperatures. As discussed above, a high return temperature triggers the cool down mode which explains the short running cycles and large number of start-ups. After some hydronic adjustments and removal of the exchanger (this is case 2.b in Table 2), the results and running hours were spectacularly improved.

However, it is experienced a trial-and-error approach does not guarantee the best solutions for a proper hydronic integration. Therefore, parallel to the measurement campaign a methodology is been developed, optimizing hydraulic integration [17].

\subsection{Fuel Cell Technologies}

There are 4 different technologies suitable for microCHP applications: the phosphoric acid fuel cell (PAFC), the alkaline fuel cell (AFC), the solid oxide fuel cell (SOFC) and the proton exchange membrane fuel cell (PEFC) [8]. However, the technologies which are commercially available on the Belgian market are the SOFC and recently also the PEMFC. In different studies the integration of the fuel cell stack within a micro-CHP system is discussed [8].

Within a fuel cell based micro-CHP working on natural gas, the following steps can be found: gas treatment, power generation and heat recovery. Within the gas treatment, desulfurization is the first step as it has a negative influence on lifetime of stack and reformer equipment. Depending on fuel cell type this differs a little, but all fuel cell based technologies have a slow start-up.

As a PEFC works only on hydrogen the natural gas needs to be reformed into hydrogen before it enters the stack. This (steam) reforming occurs at high temperatures (about $700^{\circ} \mathrm{C}$ ) and after that two gas shift reactors are necessary to withdraw $\mathrm{CO}$ and $\mathrm{CO} 2$ out of the gas flow as $\mathrm{CO}$ poisons the membrane of the PEFC. The gas reforming therefore needs heat. A smart heat integration can improve overall efficiency so waste heat can be used, but the start-up of the reforming process takes about 10 minutes.

For SOFC technology the steam is mixed in the gas supply and heated before entering the stack, the reforming can take place before but also in the stack as the stack works on a high temperature. Because the reaction needs, like the reforming, a high temperature, the heating of the stack causes a slow start-up. Part load is possible with acceptable electric efficiencies, thermal power output drops however, more rapidly.

Because of these limitations it is wise to operate also the fuel cell as constant as possible at nominal load. This is done in the examined case where high electrical efficiencies were achieved. One drawback needs to be tackled though, as efficiency drops over time by $10 \%$ /year due to degradation (from $57 \%$ to $45 \%$ in 1,5 years). A smooth operation, but also a thorough gas treatment help to limit this degradation rate. As little effort is yet devoted to an optimal thermal integration of this type, further improvement is definitely possible regarding thermal efficiency.

In general, regarding hydronics, one should ensure a priority for the CHP and always take the complete design into account when performing adjustments, as it is crucial to understand the net heat demand before implementing a CHP.

\section{Conclusions}

A comparison is made between reported and actual measured efficiencies for different kinds of micro-CHP. Next, an extended review on their part load behaviour is given. Based on the performed measurements the ICEbased micro-CHPs are most reliable, although a good hydronic design is crucial. The Stirling loses in practice (almost) all its saving potential due to poor part load behaviour and stand-by losses of the storage tanks. If the degradation rate drops for fuel cells they are to be the future number one for micro-CHP, as thermal improvements are definitely possible.

\section{Acknowledgements}

The authors would like to thank the government of Flanders who funded this research within VLAIOTETRA and also Cogen Vlaanderen vzw and a large consortium of Flemish companies who supported the research by means, data and feedback.

\section{References}

[1] C. Brandoni, A. Arteconi, G. Ciriachi, and F. Polonara, Energy Convers. Manag., 87 (2014).

[2] H. Lund and E. Münster, Renew. Energy, 28, 14 (2003).

[3] C. Shao, C. Li, X. You, H. Wu, J. Zhang, Y. Ding, and Y. Song, Energy Procedia, 103 (2016)

[4] VREG, "Energiebesluit.” p. artikel 1.1.1, §2, $66^{\circ}$.

[5] O. A. Shaneb, G. Coates, and P. C. Taylor, Energy Build., 43, 8 (2011).

[6] D. Streimikiene and T. Baležentis, Renew. Sustain. Energy Rev., 26 (2013).

[7] I. Verhaert, S. Verhelst, H. Huisseune, I. Poels, G. Janssen, G. Mulder, and M. De Paepe, Appl. Therm. Eng., 40 (2012).

[8] I. Verhaert, G. Mulder, and M. De Paepe, Energy Convers. Manag., 126 (2016).

[9] U. Arndt, U., Beausoleil-Morrison, I., et al. Annex 42 (2007).

[10] J. Bouvenot, et al. Energy Build., 84 (2014).

[11] I. Lombardi, K., Ugursal, V.I. \& BeausoleilMorrison, Appl. Energy, 87, 10 (2010).

[12] S. Siblio and A. Rosato, Appl. Therm. Eng, 52 (2013). 
[13] J. Y. Wu, X. Q. Zhai, G. Yang, and R. Z. W. C. Y. Zheng Energy, 101 (2016)

[14] R. B. De Rougé, T. Tirtiaux, P. Picard, and P. Stabat, Proc. of REHVA, Aalborg (2016).

[15] S. Sibilio and A. Rosato, Appl. Therm. Eng, 4546 (2012).

[16] http://www.microwkk.be (available on line since september 2016)

[17 F. Van Riet, E. Janssen, G. Steenackers and I. Verhaert, Appl. Thermal Eng.,148,1246-1257 (2019) 